\title{
Comparison: The Effect of Ephedrine and Phenylephrine in Treatment of Hypotension after Spinal Anesthesia during Cesarean Section
}

\author{
Dr. Asim Shekhar ${ }^{1}$, Dr. OlvynaD’ Souza ${ }^{2}$ \\ Department of Anaesthesiology, MGM Medical College and Hospital, KamotheNavi Mumbai
}

\begin{abstract}
Background and Objective: The effectiveness of ephedrine and/or phenylephrine, in treatment of hypotension secondary to spinal anesthesia for cesarean section and their effects on fetal/neonatal outcome were studied. Methods and Materials: Sixty healthy parturients were randomly assigned to two groups; Group $A(n=30)$ received boluses $5 \mathrm{mg} / \mathrm{ml}$ increments Ephedrine and, Group B $(n$ = 30) received a boluses of phenylephrine $20 \mu \mathrm{g} / \mathrm{ml}$ increments for treatment of hypotension after spinal block during cesarean section. Changes in maternal blood pressure and heart rate, and incidence of nausea-vomiting, neonatal Apgar score at 1 and 5 minutes of delivery, and umbilical arterial blood gas values were recorded. Results: There were no differences in treatment of hypotension following sympathectomy after spinal block with two drugs. Neonatal outcome was similar in two groups. There were not significant differences in umbilical arterial values in two groups. Conclusion: Ephedrine and phenylephrine are both effective vasopressors for treatment of hypotension associated to spinal block during cesarean section without adverse effects on infants/neonates.
\end{abstract}

Keywords: Cesarean Section; Spinal Anesthesia; Hypotension; Ephedrine; Phenylephrine; Fetal/Neonatal Outcome

\section{Introduction}

Hypotension is perhaps the most common complication of neuraxialanesthesia in obstetric patients. It has been estimated to occur in approximately $30 \%-90 \%$ of cases .

Maternal hypotension produces unpleasant symptoms such as nausea, vomiting, and lightheadedness. More importantly, when severe and sustained, hypotension can impair uterine and intervillous blood flow and ultimately result in fetal acidosis and neonatal depression

Prevention measures include fluid preload, left lateral tilt, and use of vasopressors.

Traditionally, Ephedrine "which has a strong $\beta$-adrenergic and a weaker $\alpha$-adrenergic effects" has been recommended in this situation, but its position has been challenged because of potential complication that supraventricular tachycardia, tachyphylaxis, and most importantly fetal acidosis.

Phenylephrine, an $\alpha$-adrenergic agonist, can be used for prevention and treatment of maternal hypotension. Moreover, phenylephrine reduces the incidence of nausea and vomiting as well as fetalacidosis, but it may cause maternal bradycardia. Present study compared ephedrine with phenylephrinein treatment (not prevention) of maternal hypotension induced spinal anesthesia regarding the maternal cardiac response to hypotension in terms maternal hemodynamic and fetal/neonatal status.

\section{Methods and Materials}

This was a prospective, double-blind, and case-controlled study. After the approval of the hospitals ethics Committee and obtaining written informed consent, 60 parturientsof ASA physical status I, age $>18$ years, undergoing elective cesareansection under spinal anesthesia.
A prior excluded were patients with classic contraindications to spinal anaesthesia, allergy to local anesthetics, preexisting systemic disease, known fetal abnormalities, and history of tacking any medications that could influencehemodynamic responses.Patients were fasted for 6 hours.

In the operating room routine standard monitoring with noninvasive arterial pressure (NIBP), electrocardiography (ECG), and pulseoximetrywas established. Baseline measurements were performed 5 minutes before spinal anesthesia. An iv cannula was introduced into a peripheral vein.

Each patient was preloaded $15 \mathrm{ml} / \mathrm{kg}$ of ringer lactate solution. With the patient in the sitting position, lumbar puncture was performed at the L3-4 or L4-5 interspaces with $2 \mathrm{ml}$ of $0.5 \%$ hyperbaric Bupivacaine via a 25-guage Quincke spinal needle. Immediately after completing the intrathecal injection, patients were positioned supine on the operating table. The level of the sensory block was evaluated by loss of Pinprick discrimination at the time to incision and every 5 minutes. Sensory block to T6 dermatome considered adequate.

Parturients were assigned to receive one of two vasopressor solutions whenever maternal systolic arterial pressure (SAP) decreased to $80 \%$ of baseline or less.

Group A received boluses $6 \mathrm{mg} / \mathrm{ml}$ increments ephedrine if there was maternal decreased heart rate (HR 20\% lower than baseline values) with a SAP $\geq 20 \%$ less than baseline;

Group B received a bolus of phenylephrine $20 \mu \mathrm{g} / \mathrm{ml}$ increments whenever there was increased heart rate( heart rate $20 \%$ higher than baseline levels).

All hemodynamic evaluations were performed at 2-minutes interval until delivery. After that, these parameters were determined at 5-minutes interval until end of surgery. 


\section{International Journal of Science and Research (IJSR) \\ ISSN (Online): 2319-7064 \\ Index Copernicus Value (2013): 6.14 | Impact Factor (2014): 5.611}

Changes in maternal BP (SAP, DAP) and HR throughout anesthesia, incidence of nausea and vomiting, total dose and the number of boluses of vasopressors, sensory block level (dermatome), and total volume of fluids, were recorded. Apgar scores at 1 and 5 minutes of delivery for all newborns were noted and a score $<8$ was considered low. Umbilical arterial blood sampling was obtained for determination of acid-base status

\section{Results}

Total 60 patients were enrolled in this study, 30 patients for Ephedrine group and 30 patients for Phenylephrine group. The groups were comparable with respect to age, weight, height, gravidity, iv fluid volume, and median level of sensory block.

Table 1: Patient's characteristics and intraoperative variables in two groups

\begin{tabular}{|c|c|c|c|}
\hline & Group A & Group B & P \\
\hline Age (yr) & $28.10 \pm 4.86$ & $29.56 \pm 4.89$ & 0.72 \\
\hline Weight (kg) & $73.42 \pm 9.48$ & $75.03 \pm 10.17$ & 0.89 \\
\hline Height (cm) & $159.53 \pm 5.50$ & $161.77 \pm 4.05$ & 0.62 \\
\hline Gestational age (wk) & $39(37-39)$ & $39(37-39)$ & 1.00 \\
\hline $\begin{array}{c}\text { Upper sensory level } \\
\text { (median, range) }\end{array}$ & T6 (T4 - T6) & T6 (T4 - T6) & 1.00 \\
\hline $\begin{array}{c}\text { Duration of anesthesia } \\
\text { (min) }\end{array}$ & $75.52 \pm 8.65$ & $73.24 \pm 8.42$ & 0.65 \\
\hline $\begin{array}{c}\text { Duration of surgery } \\
\text { (min) }\end{array}$ & $54.46 \pm 6.61$ & $51.71 \pm 6.85$ & 0.82 \\
\hline $\begin{array}{c}\text { Total fluid during } \\
\text { anesthesia (ml) }\end{array}$ & $1850 \pm 120$ & $2050 \pm 150$ & 0.75 \\
\hline $\begin{array}{c}\text { Total dose of } \\
\text { vasopressor }\end{array}$ & $8.36 \pm 0.85(\mathrm{mg})$ & $23.33 \pm 8.96$ \\
$(\mu \mathrm{g})$ & - \\
\hline $\begin{array}{c}\text { Number of vasopressor } \\
\text { administration }\end{array}$ & $2(1-3)$ & $2(1-2)$ & 0.25 \\
\hline $\begin{array}{c}\text { Incidence of nausea- } \\
\text { vomiting (\%) }\end{array}$ & $5(15.1)$ & $2(7.1)$ & 0.34 \\
\hline
\end{tabular}

Table 2: Neonatal outcome in two groups

\begin{tabular}{|c|c|c|c|}
\hline Apgar score at: & GroupA & Group B & P \\
\hline $1 \mathrm{~min}$ & $8.46 \pm 0.32$ & $8.58 \pm 0.30$ & 0.22 \\
\hline $5 \mathrm{~min}$ & $9.70 \pm 0.59$ & $9.86 \pm 0.40$ & 0.15 \\
\hline $\begin{array}{c}\text { Apgar score }<8 \text { at 1 and 5 min } \\
\text { Umbilical artery blood gas } \\
\text { analysis: }\end{array}$ & 0 & 0 & - \\
\hline $\mathrm{pH}$ & $\begin{array}{c}7.26(7.24- \\
\end{array}$ & $\begin{array}{c}7.28(7.25- \\
7.32)\end{array}$ & 0.12 \\
\hline $\mathrm{PCO}(\mathrm{mmHg})$ & $51(48-57)$ & $53(49-66)$ & 0.26 \\
\hline $\mathrm{PO} 2(\mathrm{mmHg})$ & $14(12-18)$ & $12(11-16)$ & 0.27 \\
\hline $\mathrm{HCO}(\mathrm{mmol})$ & $23(18-22)$ & $21(16-23)$ & 0.61 \\
\hline Base deficit $(\mathrm{mmol})$ & $1.6(0.1-2.3)$ & $1.9(0.3-3.2)$ & 0.20 \\
\hline
\end{tabular}

\section{Discussion}

In this study, we showed that there was no difference between ephedrine and phenylephrine in their efficacyfor managing hypotension in healthy parturients undergoing cesarean section. In addition, results of our study have shown that the neonatal outcome was similar betweengroups. There were no differences in Apgar scores at 1 and 5 minutes of birth. So that, there were differences between groups in umbilical artery $\mathrm{pH}$ and base excess values. The severity of these differences was small and true acidosis $(\mathrm{pH} \leq 7.20)$ was not seen in any of neonates.

The prevention and treatment of maternal hypotensioninduced spinal anesthesia remains the most important problem, with no consensus to the optimal mode of management.

Clinical data have suggested that $\alpha$-adrenergic agonists such as ephedrine or phenylephrine may be given safely for prevention or treatment of hypotension during administration of regional anesthesia for cesarean section. Earlier studies have confirmed the beneficial phenylephrine effects on umbilical $\mathrm{pH}$, as phenylephrine has been recently the first line drug for this purpose. However, more recent studies results show that some caution with the use of phenylephrine may be warranted.

Although phenylephrine is efficient for managing blood pressure, it causes reflexes bradycardia and it may reduce cardiac output. The clinical significance of this, is more reduction of utero-placental blood flow. Ephedrine also is associated with tachycardia.

Unlike of the previous studies, a recent study reported that phenylephrine was associated with higher values of fetal lactate. There is evidence that fetal lactate may be a better predictor of severe neonatal morbidity than $\mathrm{PH}$. In the study by NganKee et al., they compared the phenylephrine with ephedrine in non-elective cesarean section. They concluded that despite small differences between groups in umbilical cord blood lactate concentration and $\mathrm{PO} 2$, there were no differences in fetal acid-base status or clinical neonatal outcome between the two vasopressors.

In this study, we didn't administer vasopressors as prophylaxis, for two reasons. First, it is not ethically right; for example we couldn't administer ephedrine to a patient had tachycardia. Second, clinical studies have not supported the prophylactic use of vasopressors for prevention of spinal hypotension.

\section{Summary}

The results of this study, shows that phenylephrine and ephedrine (with respect to maternal hemodynamic changes) are both efficient and suitable vasopressors for treatment (not prophylaxis) hypotension following spinal block in patients undergoing caesarean section. Both drugs have similar effects on neonates.

\section{References}

[1] Chestnut, D.H. (2009) Chestnut's obstetric anesthesiaprinciples and practice. 4th Editon, Mosby, Philadelphia.

[2] Rasanen, J., Alahuhtat, S., Kangas-Saarelat, T., Jouppilat, R. and Jouppila, P. (1991) The effects of ephedrine and etilefrine on uterine and fetal blood flow and on fetalmyocardial function during spinal anaesthesia for caesarean section. International Journal of Obstetric Anesthesia, 1, 3-8. doi:10.1016/0959289X(91)90022-I

\section{Volume 4 Issue 12, December 2015}




\section{International Journal of Science and Research (IJSR) \\ ISSN (Online): 2319-7064}

Index Copernicus Value (2013): 6.14 | Impact Factor (2014): 5.611

[3] Loughrey, J.P.R., Yao, N., Datta, S., Segal, S., PianSmith, M. and Tsen, L.C. (2005) Hemodynamic effects of spinal anesthesia and simultaneous intravenous bolus of combined phenylephrine and ephedrine versus ephedrine for cesarean delivery. International Journal of Obstetric Anesthesia, 14, 43-47. doi:10.1016/j.ijoa.2004.07.011

[4] Miller, R.D. (2010) Miller, s anesthesia. 7th Edition, Churchill Livingstone, Philadelphia.

[5] Adigun, T.A., Amanor-Boadu, S.D. and Soyannwo, O.A. (2010) Comparison of intravenous ephedrine with phenylephrine for the maintenance of arterial blood pressure during elective caesarean section under spinal anaesthesia. African Journal of Medicine \& Medical Sciences, 39, 13-20.

[6] NganKee, W.D., Khaw, K.S., Ng, F.F. and Lee, B.B. (2004) Prophylactic phenylephrine infusion for preventing hypotension during spinal anesthesia for cesarean delivery.Anesthesia\& Analgesia, 98, 815-821. doi:10.1213/01.ANE.0000099782.78002.30 